\section{POTENCIAL ALELOPÁTICO E IDENTIFICAÇÃO DE COMPOSTOS SECUNDÁRIOS EM EXTRATOS DE CALOPOGÔNIO (Calopogonium mucunoides) UTILIZANDO ELETROFORESE CAPILAR.}

\author{
Santos, S. , Moraes, M.L.L ${ }^{\mathrm{II}}$; Rezende, M.O.O.'; Souza Filho, A.P.S ${ }^{\mathrm{III}}$ \\ I- Instituto de Química de São Carlos- Universidade de São Paulo, USP, CP 780, CEP 13560- \\ 970, São Carlos, SP. \\ II-Departamento de Ciências Exatas e da Terra - Universidade Federal de São Paulo, UNIFESP, \\ CEP 09972-270, Diadema, SP. \\ III-Empresa Brasileira de Pesquisa Agropecuária - Embrapa Amazônia Oriental, CP 48, CEP \\ 66095-100, Belém, PA.
}

\section{Resumo}

Neste trabalho avaliou-se o potencial alelopático de extratos orgânicos obtidos a partir das folhas de Calopogonium mucunoides sobre a germinação de sementes de algumas plantas daninhas comumente encontradas em áreas de pastagens cultivadas da Amazônia brasileira, as quais causam grandes danos à produtividade: Cassia tora (mata-pasto), Mimosa pudica (malícia) e Cassia occidentalis (fedegoso). Compostos secundários foram identificados e quantificados nos extratos brutos utilizando eletroforese capilar. Após identificar e quantificar os compostos presentes nos extratos realizaram-se novos bioensaios com os padrões dos compostos identificados a fim de verificar se os mesmos poderiam atuar como inibidores na germinação das sementes das plantas daninhas em estudo. Calopogonium mucunoides apresentou potencial 
alelopático o qual variou com a espécie de planta daninha estudada. Os protocolos desenvolvidos utilizando eletroforese capilar se mostraram eficientes e bastante específicos, sendo possível a separação e identificação de 5 classes de compostos nos extratos brutos sem necessidade de "clean up" ou fracionamento dos mesmos, com análises rápidas (em menos de 20 minutos) e baixas quantidades de solventes utilizadas quando comparadas aos métodos tradicionais de análises. Vários dos compostos identificados apresentaram potencial de inibição de germinação nas sementes estudadas, sendo malícia a mais sensível, os bioensaios também indicaram certo efeito sinérgico ao utilizar a mistura de compostos.

Palavras chave: alelopatia, eletroforese capilar, plantas daninhas

\section{Introdução}

Vários fatores têm limitado um maior desenvolvimento da bovinocultura no Brasil dentre eles destacam-se: conhecimento precário da ecologia e do valor nutritivo de forrageiras, limitada tecnologia, falta de conhecimento das características do solo, má qualidade das pastagens, incluindo aí o aparecimento de plantas daninhas, as quais causam consideráveis perdas refletindo na redução da produtividade e qualidade do produto, afetando, desta forma, o mercado consumidor.

Com o intuito de eliminar plantas daninhas, insetos e outras pragas, os criadores utilizam vários agroquímicos sintéticos. Muitos pesticidas são altamente tóxicos ao homem e a outros animais, seja por exposição direta ou devido à acumulação no organismo mediante a ingestão de alimentos contaminado. Além de problemas ambientais e da toxicidade desses compostos ao homem, muitos sistemas agrícolas têm apresentado redução expressiva no poder de controle dos herbicidas sintéticos [1].

Neste sentido, a alelopatia pode ser de grande importância, pois possibilita a identificação de compostos, os quais poderão servir como base para a produção de herbicidas mais específicos e menos prejudiciais ao ambiente quando comparados àqueles em uso atualmente na agricultura [2-5]. 
Entre a grande variedade de metabólitos secundários encontrados nas plantas, os fenólicos e terpenóides apresentam a maior parte dos compostos com atividades alelopáticas identificados. Compostos aromáticos tais como fenóis, ácidos fenólicos, derivados do ácido cinâmico, cumarinas, flavonóides, catequinas, quinonas e taninos também têm sido identificados como agentes alelopáticos [3,5-8].

As técnicas analíticas normalmente empregadas nas análises de extratos vegetais são as cromatográficas. A aplicação de tais técnicas, porém, constitui-se, ainda, em um procedimento que consome tempo razoável podendo tornar-se tedioso, especialmente quando se envolvem misturas complexas como extratos de plantas.

A eletroforese capilar (CE) tem sido considerada para análise de extratos de plantas e óleos essenciais, principalmente porque permite a injeção direta dos extratos sem necessidade de purificação dos princípios ativos, utilização de volumes reduzidos de amostras, baixo consumo de reagentes e automação das análises [9-11].

A configuração instrumental básica consiste de uma fonte de alta tensão, capilares (o mais utilizado é o de sílica fundida), eletrodos (usualmente, platina) e um detector apropriado. As extremidades do capilar são imersas em reservatórios contendo um eletrólito adequado, sendo preenchidas com o mesmo. Uma fonte de alta tensão é usada para estabelecer o campo elétrico, sendo conectada através dos eletrodos aos dois reservatórios [11-14].

Protocolos em eletroforese capilar estão sendo aplicados à extratos vegetais com o objetivo de identificar e quantificar várias classes de metabólitos secundários, mostrando-se bastante específicos $[15,16]$.

O procedimento consiste em injetar o extrato vegetal sem purificação prévia, sob determinadas condições, as quais favoreçam a ionização e separação de determinadas classes de compostos.

A seguir apresenta-se uma breve descrição dos protocolos utilizados na identificação de algumas classes de metabólitos secundários estudados neste trabalho.

-Protocolo I - tampão fosfato de sódio pH 2,5

Neste valor de $\mathrm{pH}$ espera-se separar e identificar compostos que absorvem luz na região UV-Vis e apresentem carga positiva. Compostos de caráter básico como é o caso dos alcalóides, vitaminas e aminoácidos podem ser separados e identificados.

-Protocolo II - 3,5-dinitrobenzoato, CTAB, pH 3,7 
Esta condição de análise pode ser utilizada para separar compostos os quais não absorvem na região UV-Vis e apresentem valores de $\mathrm{pK}_{\mathrm{a}}$ menores que 5. Neste caso um agente cromóforo é utilizado como parte do eletrólito, para que seja possível a detecção indireta do analito pelo detector de UV/Vis. Ácidos orgânicos de baixa massa molar são separados utilizando tal procedimento.

-Protocolo III - tampão fosfato de sódio, pH 6,5.

Utilizando este protocolo, compostos aniônicos que apresentem absorção na região UV-Vis e valores de pKa menores ou próximos de 6,5 (ânions orgânicos) podem ser separados. Compostos com grupos hidroxila vicinais podem ser analisados nesta condição. Exemplo: ácido ferúlico, clorogênico, cafeico, p-anísico entre outros

-Protocolo IV - tampão tetraborado de sódio, pH 9,4.

Sob tal condição é possível separar compostos aniônicos que absorvam luz UV-Vis e apresentam valores de $\mathrm{pK}_{\mathrm{a}}$ menores ou próximos de 9,4, isto aqueles compostos que possam ser ionizados neste valor de $\mathrm{pH}$. Quercetina, rutina, naringenina entre outros, são exemplos de flavonóides separados e detectados de acordo com este protocolo.

-Protocolo V - tampão tetraborato de sódio, SDS, pH 9,4.

Pode-se separar compostos neutros os quais absorvem na região UV-Vis por partição entre a solução aquosa e a micelar (SDS).

Esta análise é feita em modo MECK, no qual se adiciona uma solução de surfactante acima de sua concentração micelar crítica. Separam-se e identificam-se nestas condições terpenos tais como: linalol e geraniol entre outros.

Calopogonium mucunoides, mais conhecido como calopo ou calopogônio, é uma planta nativa da América do Sul tropical da família das leguminiosas. É utilizado para pastoreio com gramíneas, mas também como pasto de corte ou para feno; pode ser utilizado, também, no combate à erosão, quando incorporado ao solo [17]. No ambiente, tal planta é relativamente livre do ataque de pragas e doenças, o que a torna um interessante objeto de estudo. Bioensaios realizados por Souza Filho demonstraram que calopogônio apresenta potencialidades 
alelopáticas em níveis que possibilitam reduções expressivas na germinação de três espécies de plantas daninhas: Desmodium adscendens (desmódio), Sida rhombifolia (guanxuma) e Vernonia polyanthes (assa peixe) [18,19].

Assim, o objetivo deste trabalho foi avaliar o potencial alelopático de extratos provenientes das folhas de calopogônio frente a algumas sementes de plantas daninhas comumente encontradas em pastagens cultivadas na Amazônia utilizando bioensaios de germinação bem como apresentar a técnica de eletroforese capilar como uma alternativa na identificação e quantificação de compostos secundários com atividade alelopática avaliando o efeito desses compostos na germinação das sementes das plantas daninhas estudadas.

\section{Material e Métodos}

\section{I-Reagentes}

Todos os reagentes utilizados foram de grau analítico. Os padrões dos compostos secundários foram obtidos da Sigma-Aldrich (St. Louis, MO, USA).

Os solventes (hexano, diclorometano, acetato de etila e metanol) foram grau HPLC, obtidos da Mallinkrodt (Paris, Kentucky), e a água utilizada no preparo das soluções foi desionizada pelo sistema Milli-Q (Millipore, Bedford, MA, USA).

II-Coleta do material

O material vegetal foi cultivado no município de Paragominas - Pará, em solo LATOSSOLO AMARELO, sem utilização de adubo, durante 3 meses. Após esse período, a parte aérea (folhas+ colmo) foi cortada rente ao solo, efetuando-se, então, a secagem do material em estufa com circulação de ar forçada $\left(39{ }^{\circ} \mathrm{C} \pm 1{ }^{\circ} \mathrm{C}\right)$ e posterior trituração em moinho tipo Willey. O material foi acondicionado em sacos plásticos para posterior extração.

As sementes das plantas daninhas utilizadas nos bioensaios foram coletadas em áreas de pastagens nos municípios de Castanhal e Paragominas, centros bem representativos da pecuária no Pará.

II-Obtenção dos extratos brutos com solventes de diferentes constantes dielétricas. 
Foram distribuídos $6,7 \mathrm{Kg}$ de folhas de calopogônio previamente secas e moídas, no interior de 5 erlenmeyers com 6 litros de capacidade, adicionando-se em seguida hexano.

Durante 15 dias procederam-se trocas diárias no solvente, concentrando o extrato obtido em rotoevaporador e recuperando o solvente, repondo, desta forma, o volume de hexano nos erlenmeyers.

Passados 15 dias, filtrou-se a mistura (folhas+solvente) utilizando funil de Buchner acoplado a bomba de vácuo, recolocando as folhas após secas (sem resíduo de hexano) de volta nos erlenmeyers e efetuando a troca do solvente por diclorometano.

Nos próximos 15 dias foram realizadas trocas diárias no diclorometano concentrando os extratos e recuperando o solvente. Passadas as duas semanas filtrou-se a mistura trocando o diclorometano por acetato de etila. Este procedimento também foi realizado com metanol.

Desta forma foram obtidos 4 extratos brutos os quais foram posteriormente testados em bioensaios com o objetivo de identificar aqueles que apresentassem atividade inibidora na germinação de sementes das plantas daninhas.

\section{III-Bioensaios}

Cada placa de Petri de 9,0 cm de diâmetro, forrada com uma folha de papel de filtro, recebeu 5,0 $\mathrm{mL}$ do extrato $(2 \% \mathrm{~m} / \mathrm{V})$, adicionando-se posteriormente, após evaporação do solvente, $2,0 \mathrm{~mL}$ de uma solução $0,2 \%$ de micostatin (para evitar proliferação de fungos nas placas) em água destilada, recebendo, então, 25 sementes. Para efeitos de comparação, foi realizado um tratamento testemunha (controle) no qual utilizaram-se apenas $5,0 \mathrm{~mL}$ do solvente utilizado nas soluções dos extratos e após a evaporação do mesmo, $2 \mathrm{~mL}$ da solução $0,2 \%$ de micostatin em água destilada, seguindo a partir daí o mesmo procedimento realizado nas placas onde se aplicaram os extratos.

$\mathrm{O}$ bioensaio foi desenvolvido em câmara de germinação à temperatura constante de $25{ }^{\circ} \mathrm{C}$ e fotoperíodo de 12 horas. A germinação foi monitorada por um período de 15 dias, com contagem diária e eliminação das sementes germinadas. A germinação das sementes das plantas daninhas: malícia, mata pasto e fedegoso foi analisada sob o aspecto percentual. Os bioensaios foram realizados em triplicata. 
Como plantas receptoras (plantas daninhas) foram utilizadas aquelas com maior freqüência de ocorrência em áreas de pastagens da região Amazônica: Cassia tora (mata-pasto), Mimosa pudica (malícia) e Cassia occidentalis (fedegoso).

Nos bioensaios utilizando os padrões dos compostos identificados nos extratos brutos utilizaramse soluções na concentração $5 \mathrm{mg} \mathrm{\textrm {L } ^ { - 1 }}$.

Os extratos e padrões foram adicionados apenas uma vez, no início dos bioensaios, sendo adicionada, a partir de então, apenas a solução de micostatin em água destilada.

\section{IV-Instrumentação}

As análises foram realizadas em um equipamento de eletroforese capilar modelo $\mathrm{HP}^{3 \mathrm{D}} \mathrm{CE}$ (Agilent Technologies, Palo Alto, CA, USA), equipado com um detector de arranjo de diodos, um controlador de temperatura e um sistema para aquisição e tratamento de dados. Os capilares de sílica fundida foram obtidos da Polymicro Technologies (Phoenix, AZ, U.S.A). As dimensões do capilar foram: $75 \mu \mathrm{m}$ de diâmetro interno, $375 \mu \mathrm{m}$ de diâmetro externo e $58,0 \mathrm{~cm}$ de comprimento total $(50,0 \mathrm{~cm}$ até o detector). No início de cada dia, o capilar foi condicionado com solução de $\mathrm{NaOH} 1 \mathrm{~mol} \mathrm{~L}^{-1}$ (5 min), seguido de água desionizada (5 min) e eletrólito (20 $\min )$.

\section{Resultados e Discussão}

I-Avaliação do potencial alelopático de extratos de Calopogonium mucunoides.

O extrato obtido com acetato de etila foi mais ativo no que diz respeito à inibição da germinação das sementes, $68,2 \%, 57,9 \%$, e $33,7 \%$ foram os resultados obtidos para malícia, fedegoso e mata pasto, respectivamente.

O extrato obtido com diclorometano também apresentou atividade alelopática. Observou-se: $42,1 \%$ de inibição para malícia, 37,6\% para sementes de fedegoso e 10,3\% de inibição para mata pasto. 
As sementes submetidas ao bioensaio na presença do extrato metanólico apresentaram inibições menores do que $10 \%$. O extrato obtido com hexano apresentou a mais baixa atividade, os valores de inibição ficaram abaixo de 5\%, não sendo, portanto, considerado potencialmente alelopático .

As sementes apresentaram diferentes comportamentos frente aos extratos. As sementes de malícia mostraram-se mais sensíveis e as sementes de mata pasto as menos sensíveis à ação dos extratos, apontando com isto certa especificidade dos mesmos.

\section{II-Separação e identificação de compostos secundários utilizando protocolos em eletroforese capilar.}

Os métodos desenvolvidos em cada protocolo foram propostos com base nas estruturas, nos valores de $\mathrm{pK}_{\mathrm{a}}$, no comprimento de onda máximo de absorção e em curvas de mobilidade versus $\mathrm{pH}$ dos compostos em estudo.

Os compostos secundários utilizados neste trabalho foram escolhidos com base na participação destes em fenômenos alelopáticos descritos em literatura.

A identificação dos compostos secundários nas amostras fez-se mediante a comparação dos tempos de migração com um padrão apropriado, por comparação dos espectros em UV/Vis dos picos obtidos nas amostras com os espectros dos padrões e por fim, adição de padrão nas amostras a fim de se confirmar a presença e a identidade dos compostos.

A utilização dos protocolos mostrou-se bastante satisfatória, uma vez que foi possível separar e identificar 5 classes de compostos utilizando as mesmas amostras dos extratos brutos, sem tratamentos prévios, reduzindo significativamente o tempo de análise total.

Os limites de detecção para os compostos estudados foram satisfatórios e variaram de $0,06 \mathrm{mg} \mathrm{\textrm {L } ^ { - }}$

${ }^{1}$ para o ácido clorogênico a $4,04 \mathrm{mg} \mathrm{L}^{-1}$ para ácido succínico. Já os limites de quantificação ficaram entre $0,18 \mathrm{mg} \mathrm{L}^{-1}$ e $21,19 \mathrm{mg} \mathrm{L}^{-1}$.

As Figuras 1 e 2 mostram os eletroferogramas da solução padrão dos compostos secundários estudados submetida ás condições de análises dos protocolos utilizando detecção direta e indireta respectivamente. 


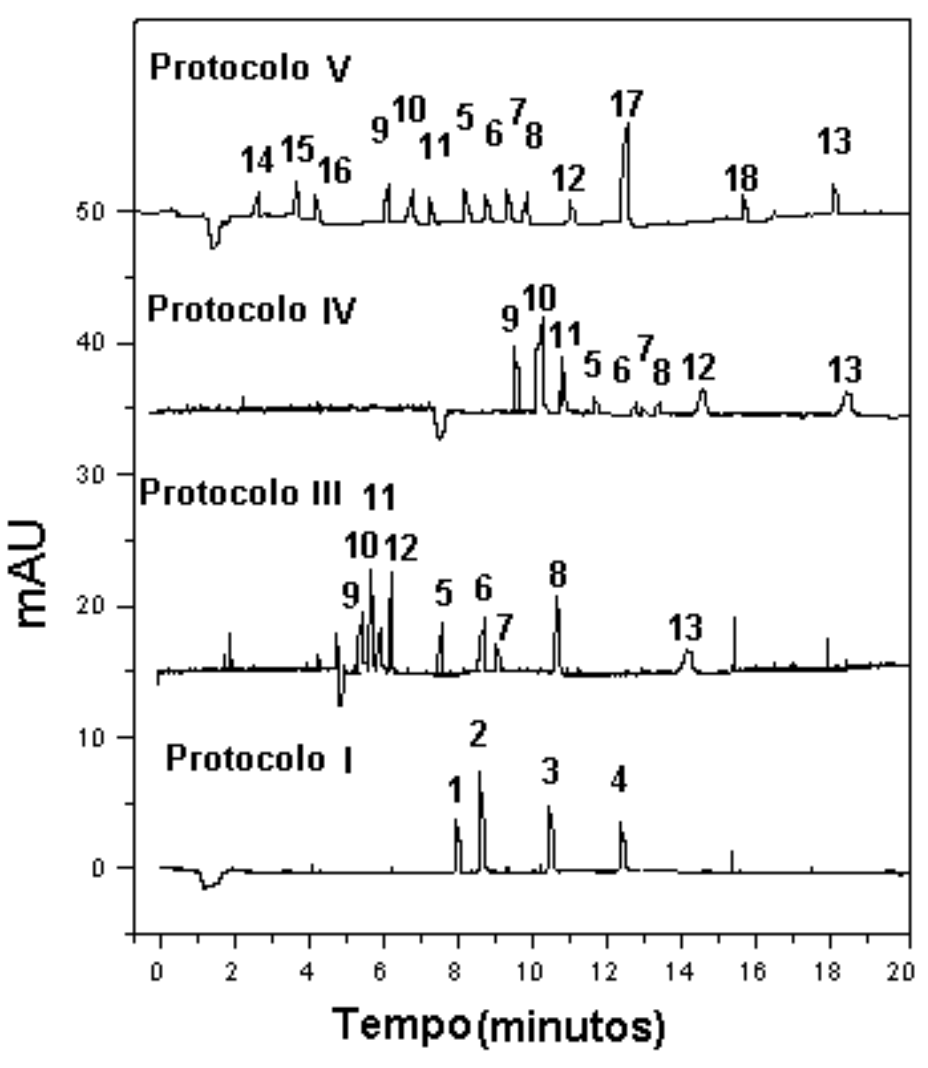

FIGURA 1 - Eletroferogramas da solução padrão submetida às condições descritas nos protocolos utilizando detecção direta. Alcalóides: 1-quinina, 2-cinconidina, 2-pilocarpina, 4atropina, Ácidos fenólicos: 5-ácido clorogênico, 6-ácido ferúlico, 7-ácido cafeico, 8- ácido panísico, Flavonóides: 9-genisteína, 10-rutina, 11-naringenina,12-canferol, 13-quercetina, Terpenos: 14-nerolidol, 15-terpineol, 16-linalol, 17-geraniol, 18-t-anetol 


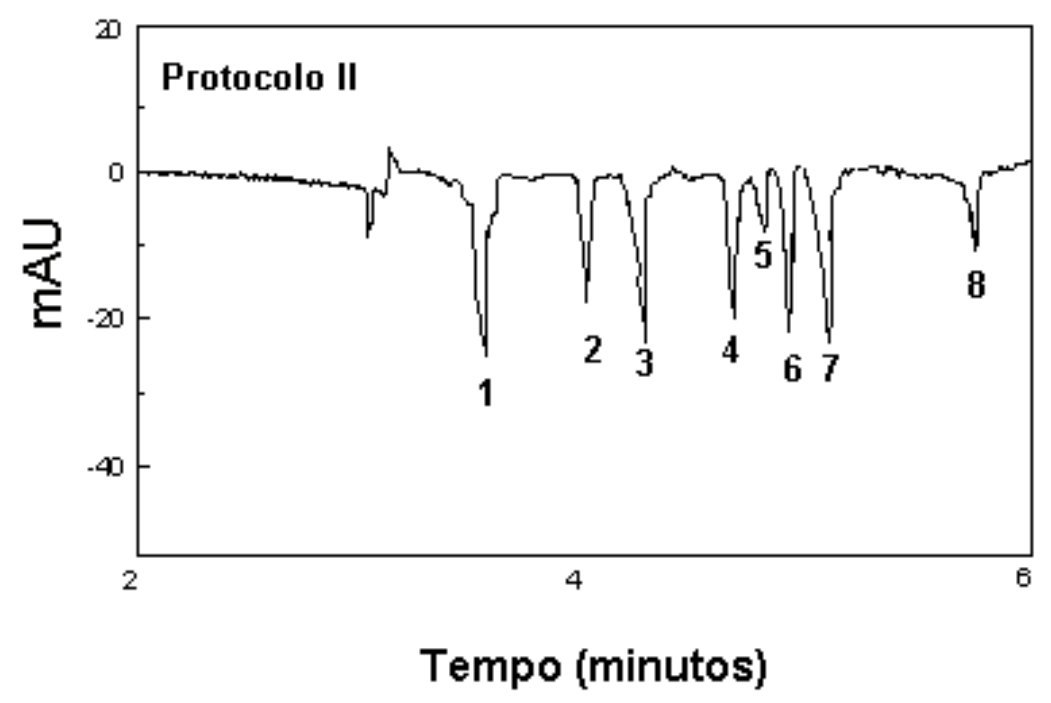

FIGURA 2 - Eletroferogramas da solução padrão submetida ao protocolo II (detecção indireta). Ácidos carboxílicos: 1-ácido oxálico, 2-ácido maleico, 3-ácido malônico, 4-ácido tartárico, 5ácido málico, 6-ácido aspártico, 7-ácido cítrico e 8-ácido succínico

A Tabela 1 apresenta os compostos identificados nos extratos bem como as concentrações encontradas.

\begin{tabular}{lll}
\hline Compostos & Extrato/diclorometano $\left(\mathbf{m g . g}^{-\mathbf{1}}\right)$ & Extrato/acetato de etila $\left(\mathbf{m g . g}^{-\mathbf{1}}\right)$ \\
\hline atropina & nd & $4,28 \pm 0,53$ \\
cinconidina & nd & nd \\
pilocarpina & nd & nd \\
quinina & nd & nd \\
ácido oxálico & nd & nd \\
ácido maleico & nd & $1,32 \pm 0,07$ \\
ácido malônico & nd & nd
\end{tabular}




\begin{tabular}{|c|c|c|}
\hline ácido tartárico & nd & $4,32 \pm 0,91$ \\
\hline ácido málico & nd & $0,21 \pm 0,06$ \\
\hline ácido aspártico & nd & $6,47 \pm 1,01$ \\
\hline ácido cítrico & nd & $0,87 \pm 0,18$ \\
\hline ácido succínico & nd & nd \\
\hline ácido clorogênico & nd & $0,50 \pm 0,02$ \\
\hline ácido ferúlico & nd & $0,75 \pm 0,03$ \\
\hline ácido cafeico & nd & $0,36 \pm 0,11$ \\
\hline ácido p-anísico & nd & $0,56 \pm 0,01$ \\
\hline genisteína & nd & $4,83 \pm 1,02$ \\
\hline rutina & nd & $1,42 \pm 0,07$ \\
\hline naringenina & nd & $1,16 \pm 0,10$ \\
\hline canferol & nd & $1,70 \pm 0,15$ \\
\hline quercetina & nd & $2,01 \pm 0,31$ \\
\hline nerolidol & nd & nd \\
\hline terpineol & nd & nd \\
\hline linalol & nd & nd \\
\hline geraniol & nd & nd \\
\hline t-anetol & nd & nd \\
\hline
\end{tabular}


TABELA 1 - Quantificação dos compostos secundários identificados nos extratos obtidos a partir das folhas de Calopogonium mucunoides

As concentrações dos compostos identificados variaram de $0,21 \mathrm{mg} \mathrm{g}^{-1}$ para ácido málico a 4,83 $\mathrm{mg} \mathrm{g}^{-1}$ para genisteína. Nenhum dos compostos estudados foram identificados no extrato obtido em diclorometano.

Não foram identificados terpenos nos extratos, tal fato já era esperado uma vez que terpenos são compostos de caráter apolar. Provavelmente tais compostos foram extraídos ao realizar a primeira extração no material vegetal utilizando hexano, solvente de baixa constante dielétrica, porém, ao realizarmos os bioensaios a fim de verificar quais extratos apresentariam atividade alelopática na inibição da germinação das sementes das plantas daninhas, observou-se que apenas os extratos de caráter mais polar: diclorometano e acetato de etila foram eficazes na inibição da germinação. Conclui-se então, que terpenos não estão envolvidos na inibição da germinação das sementes estudadas neste trabalho.

\section{III-Potencial alelopático dos compostos secundários identificados.}

Após identificação dos compostos presentes nos extratos realizaram-se bioensaios com os mesmos a fim de verificar se tais metabólitos poderiam estar atuando na inibição da germinação das sementes de plantas daninhas estudadas. Os bioensaios foram realizados utilizando soluções de cada composto e soluções com misturas dos compostos identificados na concentração $5 \mathrm{mg} \mathrm{L}^{-}$ 1 
A Figura 3 mostra os resultados obtidos nos bioensaios de germinação ao utilizar solução com os alcalóides identificados nos extratos.

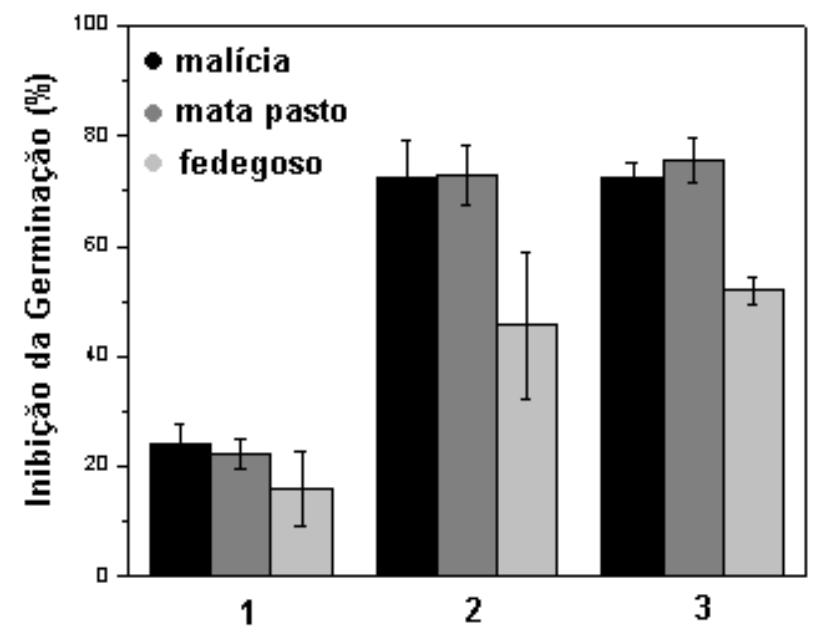

FIGURA 3 - Inibição da germinação das sementes das plantas daninhas frente aos alcalóides identificados nos extratos: 1.cinconidina, 2.atropina, 3.mistura dos padrões de alcalóides

Atropina foi mais eficaz na inibição da germinação das sementes de plantas daninhas quando comparada a cinconidina, as sementes de malícia e mata pasto foram as mais sensíveis a ambos os compostos. Ao realizarmos bioensaio utilizando uma solução na qual se acrescentaram os dois compostos, observa-se um ligeiro aumento do efeito inibitório sobre as sementes de mata pasto e fedegoso.

Ao utilizar ácidos fenólicos foi observada maior sensibilidade das sementes de malícia, os valores de inibição variaram de: 5,1\% para as sementes de mata pasto a 53,4\% para sementes de malícia submetidas à solução de ácido ferúlico.

As sementes de fedegoso não sofreram inibição quando expostas aos ácidos: cafeico e p-anísico. Observa-se aumento de inibição de germinação de todas as sementes ao utilizar uma mistura com os ácidos fenólicos detectados nos extratos. 
A Figura 4 apresenta os resultados obtidos com ácidos fenólicos.

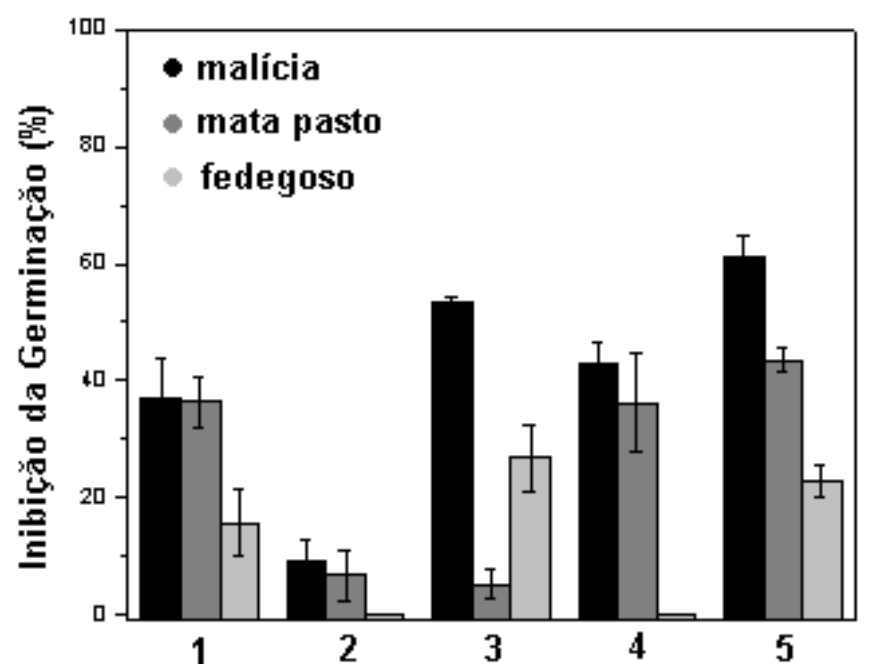

FIGURA 4 - Inibição da germinação das sementes das plantas daninhas frente aos ácidos fenólicos identificados nos extratos: 1.ácido clorogênico, 2.ácido cafeico, 3.ácido ferúlico, 4.ácido p-anísico, 5.mistura dos padrões de ácidos fenólicos

Com relação aos ácidos carboxílicos, não foi constatada inibição de germinação ao utilizar-se o ácido malêico e aspártico para nenhuma das sementes utilizadas nos bioensaios. Os ácidos tartárico, málico e cítrico mostraram-se ativos no que diz respeito à inibição de germinação apenas das sementes de malícia, sendo os valores de inibição menores que $20 \%$. Ao utilizarmos a mistura de todos os ácidos carboxílicos, observou-se inibição da germinação de todas as sementes utilizadas, os valores obtidos foram: 26,30 e $35 \%$ para as sementes de malícia, mata pasto e fedegoso respectivamente. 
A Figura 5 apresenta os resultados obtidos ao utilizarmos ácidos carboxílicos nos bioensaios.

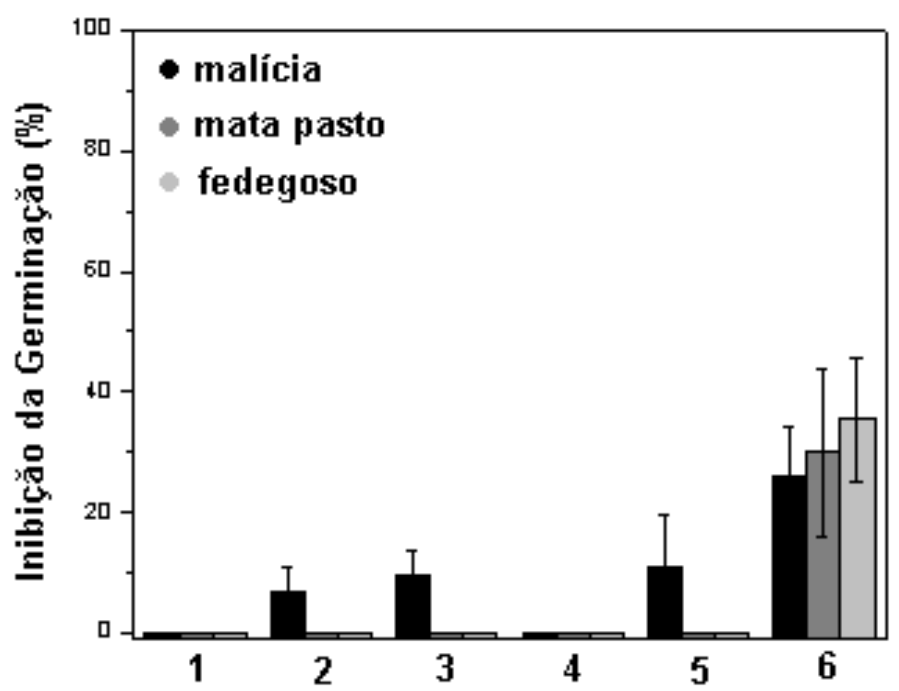

FIGURA 5 - Inibição da germinação das sementes das plantas daninhas frente aos ácidos carboxílicos identificados nos extratos: 1.ácido malêico, 2.ácido tartárico, 3.ácido málico, 4.ácido aspártico, , 5.ácido cítrico, 6.mistura de padrões de ácidos carboxílicos

A Figura 6 apresenta os resultados obtidos ao utilizar soluções dos flavonóides identificados.

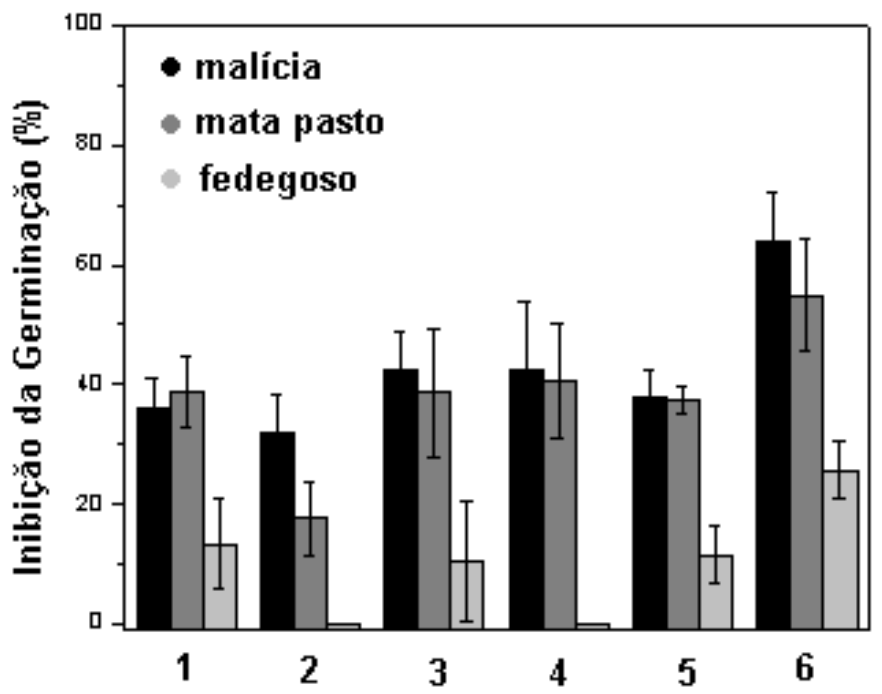

FIGURA 6 - Inibição da germinação das sementes das plantas daninhas frente aos flavonóides identificados nos extratos: 1.genisteína, 2.rutina, 3.naringenina, 4.caempferol, 5.quercetina, 6.mistura dos padrões de flavonóides 
Ao observar a figura 6 constata-se que genisteína, naringenina e quercetina foram eficazes na inibição da germinação de todas as sementes, os valores de inibição variaram de 10,6 ao utilizar naringina em sementes de fedegoso a 42,6 quando utilizou-se naringenina nas sementes de malícia. Rutina e canferol não se mostraram ativas na inibição da germinação das sementes de fedegoso. Para este caso também observa-se aumento na porcentagem de inibição de germinação ao utilizarmos a mistura dos flavonóides quando comparado aos bioensaios utilizando soluções de apenas um dos compostos identificados nos extratos.

\section{Conclusão}

Concluímos com este trabalho que a leguminosa Calopogonium mucunoides apresenta potencial alelopático. O potencial alelopático observado variou com a espécie de planta daninha estudada, sendo a espécie Mimosa pudica (malícia) a mais sensível, o que demonstrou especificidade dos extratos.

A utilização de protocolos em eletroforese capilar para separação e identificação de compostos secundários em plantas mostrou-se satisfatória uma vez que obtivemos baixos limites de detecção e quantificação e boas separações dos compostos.

Foram detectados e identificados com sucesso, flavonóides, alcalóides, ácidos fenólicos e ácidos carboxílicos nos extratos brutos sem necessidade de "clean up" ou fracionamento dos mesmos, com análises rápidas (em menos de 20 minutos) e baixas quantidades de solventes utilizadas quando comparadas aos métodos tradicionais de análises.

Com relação às atividades alelopáticas dos compostos, observaram-se valores de inibição de germinação menores que $50 \%$ para quase todos os compostos com exceção de ácido ferúlico aplicado em sementes de malícia e atropina nos bioensaios com sementes de malícia e mata pasto. Para todos os compostos estudados observou-se aumento na inibição da germinação de todas as sementes ao utilizar soluções com misturas dos mesmos quando comparados aos bioensaios nos quais utilizou-se soluções contendo apenas um dos compostos identificados nos extratos. Exceção ocorreu apenas para as sementes de fedegoso, nas quais a inibição de germinação ao utilizar solução de ácido ferúlico foi um pouco maior $(26,9 \%)$ do que quando utilizou-se a solução padrão mista de todos os ácidos fenólicos $(22,8 \%)$. 
Confirmou-se o potencial alelopático dos flavonóides (genistein, quercetina, naringenina, caempferol rutina) bem como dos ácidos fenólicos (clorogênico, p anísico, ferúlico e cafeico) descritos em literatura .

\section{Agradecimentos}

Os autores agradecem á FAPESP (01/14123-0) e CAPES pelo suporte financeiro.

\section{Referências Bibliográficas}

[1] P.J. Christoffoleti; F.J. Ovejero; J.C. Carvalho, Aspectos de resistência de plantas daninhas a herbicidas. s.ed., Campinas, 2004.

[2] L.A. Anaya, Crit. Rev. Plant Sci. 186 (1999) 697.

[3] F.A. Einhelig, Handbook of natural pesticides methods. CRC Press, Florida, 2000.

[4] R.J. Vyvyan, Tetrahedron 58 (2002).

[5] C.B. Silva; E. Simionatto, Quim. Nova. 329 (2009) 2373.

[6] L.T. Lobo; C.F.C. Castro; M.S.P. Arruda; M.N. Arruda, Quim. Nova. 313 (2008) 493.

[7] F.M.C.B. Barros; E.O. Zambarda; B.M. Heinzmann; C.A. Mallman, Quim. Nova 324 (2009) 861.

[8] N. Dudai; M. Poljakolf; A.M. Mayear; E.J. Putiesvsky, J. Chem. Ecol. 255 (1999) 1079.

[9] N.A. Assunção; J.H. Bechara; A.V.C. Simionato; M.F.M. Tavares, Quim. Nova 318 (2008) 2124.

[10] L. Suntornsuk, J. Pharm. Biom. Anal. 25 (2002) 679.

[11] M.F.M. Tavares, Quím. Nova 162 (1996) 173.

[12] D.R. Baker, Capillary electrophoresis. John Wiley \& Sons, New York, 1995.

[13] N.A. Guzman, Capillary Electrophoresis Technology. Marcel Dekker, New York, 1993.

[14] G.W. Ewing, Analytical Instrumentation Handbook. Marcel Dekker, New York, 1997.

[15] S. Santos; M.L.L. Moraes; A.P.S.; Souza Filho; M.O.O Rezende, J. Environ Sci. Health, B40 1 (2005) 77. 
[16] S. Santos; M.L.L. Moraes; A.P.S.; M.O.O Rezende, Eclét. Quim. 324 (2007) 13.

[17] G. Bufarah; B.P. Alcântara, Plantas forrageiras, gramíneas e leguminosas. Nobel, São Paulo, 1999.

[18] A.P.S. Souza Filho, SOUZA FILHO, A.P.S. Tese (Doutorado)-Faculdade de Ciências Agrárias e Veterinária, Universidade Estadual Paulista, Jaboticabal, (1995) 137p.

[19] A.P.S. Souza Filho; S.M. Alves; F.J.C. Figueiredo, Planta Daninha 212 (2003) 211.

\begin{abstract}
In this paper we describe the assessment of the possible allelopathic potential of organic extracts obtained from leaves of Calopogonium mucunoides under laboratory conditions, after that some secondary compounds were identified and quantified using capillary electrophoresis. After the identification and quantification of the compounds, we studied the effects of these compounds on the germination of some common weed, which are actually becoming a real problem in pastures in the state of Pará - Brazil. Calopogônio presented allelopathic potential. The organic crude extracts obtained from solvents with high dielectric constants (dichloromethane and ethyl acetate) were the most efficient in the inhibition of the weed germination. Seeds of Mimosa pudica were more affected by the extracts; this fact reveals the specificity of the organic extracts obtained. Capillary electrophoresis protocols were highly specific, which makes it possible to identify 5 classes of compounds using the same crude extract samples and analyze them fartly (up to 20min). Many of identified compounds show inhibitory effect in the weeds germination, seeds of malicia were the most sensible, the bioassays with the misture of compounds indicated the possibility of synergic effect.
\end{abstract}

Key Words: allelopathy, capillary electrophoresis, weeds 